\title{
Manipulating Crystallographic Texture of Sn Coatings by Optimization of Electrodeposition Process Conditions to Suppress Growth of Whiskers
}

\author{
PIYUSH JAGTAP ${ }^{1}$ and PRAVEEN KUMAR ${ }^{1,2}$ \\ 1.-Department of Materials Engineering, Indian Institute of Science, Bangalore 560012, India. \\ 2.—e-mail: praveenk@materials.iisc.ernet.in
}

The effects of two major electrodeposition process conditions, electrolyte bath temperature and current density, on the microstructure and crystallographic texture of pure tin coatings on brass and, ultimately, on the extent of whisker formation have been examined. The grain size of the deposited coatings increased with increasing electrolyte bath temperature and current density, which significantly affected the dominant texture: (211) or (420) was the dominant texture at low current densities whereas, depending on deposition temperature, (200) or (220) became the dominant texture at high current densities. After deposition, coatings were subjected to different environmental conditions, for example isothermal aging (room temperature, $50^{\circ} \mathrm{C}$, or $150^{\circ} \mathrm{C}$ ) for up to 90 days and thermal cycling between $-25^{\circ} \mathrm{C}$ and $85^{\circ} \mathrm{C}$ for 100 cycles, and whisker growth was studied. The $\mathrm{Sn}$ coatings with low Miller index planes, for example (200) and (220), and with moderate aging temperature were more prone to whiskering than coating with high Miller index planes, for example (420), and high aging temperature. A processing route involving the optimum combination of current density and deposition temperature is proposed for suppressing whisker growth.

Key words: Tin whiskers, electrodeposition, electrodeposition process conditions, crystallographic texture

\section{INTRODUCTION}

Whiskers and hillocks grow spontaneously from electro-deposited tin coatings. ${ }^{1-5}$ Whisker growth results in many serious short-term and long-term reliability issues in the electronic assemblies used in critical applications, for example aviation and space, defense, medical devices, etc., in which whisker-induced electrical short circuits and mass redistribution in conductors have resulted in complete failure of commercial satellites, defense systems, and medical equipments. ${ }^{6,7}$ Alloying with $\mathrm{Pb}$ has been reported to reduce the extent of whisker formation on $\mathrm{Sn}$ coatings ${ }^{7-10}$; this effect has been

(Received July 14, 2014; accepted December 31, 2014; published online January 21, 2015) attributed to substantial reduction of the maximum compressive stress generated in Sn coatings on addition of $\mathrm{Pb}^{9,10}$ However, the worldwide acceptance of the European Union's Restriction of Hazardous Substances (RoHS) Act-2006 prescribing complete elimination of $\mathrm{Pb}$ from all electronic components ${ }^{11}$ has resulted in re-emergence of reliability issues associated with tin whiskering.

Whisker growth is a complex process and has been reported to depend on a variety of factors, for example grain size and shape, coating thickness, alloying, composition of substrate, and externally applied stress. $^{12-15}$ Many mechanistic models for whisker growth, generally asserting that whiskering is a stress-relaxation process and relying on a self-sustaining source of continuous feed material at the whisker root, have been proposed;,12-19 however, 
there is still no single universally accepted mechanism which completely explains whisker growth. Much of the debate on the mechanism arises from the lack of understanding of the mechanistic dependence of whiskering on the microstructure and the crystallographic texture of Sn. Nevertheless, it is well established that whiskers grow to relieve the compressive stress present in coatings. ${ }^{5,12-18}$ Stress can be generated in polycrystalline tin coatings as a result of several factors. Stress can broadly be divided into two categories: global stress and localized stress. ${ }^{20}$ Global stress arises because of several factors, for example formation of intermetallic compounds (IMC) at substrate-Sn interfaces, residual stress as a result of the deposition process, thermomechanical stress because of mismatch of the coefficients of thermal expansion (CTE) of $\mathrm{Sn}$ and the substrate, and externally applied stress. Localized stress, in contrast, mainly occurs as a result of the elastic and thermal anisotropy of Sn crystals. ${ }^{21,22}$ Both of these types of stress result in mass transport of Sn atoms from the highly stressed region to the whisker root; this is generally accepted as the phenomenon driving growth of tin whiskers and hillocks. ${ }^{18,21}$ Because stress, global or local, also depends on crystallographic texture, which may be predominantly determined by electrodeposition process conditions, for example current density, deposition temperature, bath agitation, etc. ${ }^{23-27}$ it is important to study such correlations; we summarize below various reports addressing these issues.

Lal and Moyer ${ }^{24}$ studied texture and residual stress in Sn deposits by use of x-ray diffraction (XRD) for a variety of methanesulfonic acid (MSA)-based bath chemistry and reported that (220) textured coatings were whisker-resistant and developed low residual tensile stress whereas the (321) and (211) textures were more whisker-prone. Sarobol et al. ${ }^{28}$ showed that the crystallographic texture of Sn coatings could be manipulated by alloying with small amounts of $\mathrm{Cu}(0.1-0.7 \mathrm{wt} . \%)$ and $\mathrm{Pb}$ (1.3-5.4 wt.\%), such that the (111) texture was predominant in pure Sn coatings and the (001) texture was predominant in $\mathrm{Sn}-\mathrm{Cu}-\mathrm{Pb}$ coatings. Lee and Lee ${ }^{18}$ reported that (200) and (220) were the preferred orientations for Sn coatings deposited at current densities of $5 \mathrm{~mA} / \mathrm{cm}^{2}$ and $35 \mathrm{~mA} / \mathrm{cm}^{2}$, respectively. They ${ }^{18}$ also proposed that, because of the crystal anisotropy of $\beta$-Sn crystals, some grains developed different out-of-plane strain, puncturing the oxide capping layer on the coatings and thus providing nucleation sites for whisker growth. Furthermore, Frye et al. ${ }^{29}$ reported that the (001) texture developed tensile zero time stress and that the (110) texture developed compressive zero time stress, and, thus, that there was a direct correlation between texture and the zero time stress in the $\mathrm{Sn}$ deposits. Also, for sputter-coated $\mathrm{Al}$ film on $\mathrm{Si}$, another system reported to be prone to whiskering, Kim et al. ${ }^{30}$ reported a correlation between residual stress and crystallographic orientation and that residual stress in the film changed from being compressive to tensile as texture changed from (200) to (111). Therefore, electrolytic composition and minor alloying can substantially affect crystallographic texture, which, in turn, can affect the amount of stress in the coatings. However, results from systematic study of such electrodeposition process conditions as electrolyte bath temperature (or substrate temperature, $T_{\mathrm{s}}$ ) and current density, on the crystallographic texture and grain morphology of Sn coatings are still not available in the literature. Changing these two process conditions may be the easiest of all suggested methods, including minor alloying and electrolyte bath composition, for manipulating crystallographic texture, and hence the extent of whisker formation by Sn coatings. In this work, therefore, we studied the effects of these two process conditions on the microstructure and crystallographic texture of Sn coatings, and eventually on whiskering. Furthermore, whisker density and process conditions were correlated and a rule-of-thumb method for choosing the optimum combination of process conditions for effective suppression whiskering by $\mathrm{Sn}$ is also proposed.

\section{EXPERIMENTAL MATERIAL AND PROCEDURES}

Pure Sn coatings were deposited on $1 \mathrm{~mm}$ thick brass (60 wt.\% Cu, 40 wt.\% Zn) substrate by electrodeposition by use of a stannous sulfate bath; the composition of the bath is given in Table I. Before electrodeposition, brass coupons of size $1 \times 1.5 \mathrm{~cm}^{2}$ were carefully sectioned by use of a slow-speed diamond saw and metallographically polished to a 0.25 $\mu \mathrm{m}$ surface finish. After polishing, the coupons were thoroughly washed with iso-propanol(IPA) to remove organic contaminants and then acid-rinsed with $20 \%$ $\mathrm{H}_{2} \mathrm{SO}_{4}$ to remove the surface oxide layer.

Pure Sn $(99.9985 \%$ purity, supplied by Alfa Aesar) was used as the anode and the brass substrate as the cathode. Both anode and cathode were kept stationary during deposition and the electrolyte was stirred with a magnetic needle to maintain uniform hydrodynamic conditions. The stirring speed of the bath was the same for all samples. The samples were deposited with constant current density ranging from $5 \mathrm{~mA} / \mathrm{cm}^{2}$ to $30 \mathrm{~mA} / \mathrm{cm}^{2}$ at a constant electrolytic bath temperature ranging from $30^{\circ} \mathrm{C}$ to $60^{\circ} \mathrm{C}$. Electrodeposition was performed for appropriate times to obtain a coating thickness of $5 \mu \mathrm{m}$. The coating thickness was calculated by use of the mass difference method, ${ }^{31}$ the accuracy of which was confirmed by cross-sectional scanning electron microscopy (SEM). Two batches of samples were prepared: the first batch of the samples were prepared using different current densities and bath temperatures and all were subjected to room temperature aging, whereas the second batch of samples were deposited at a bath temperature of $40^{\circ} \mathrm{C}$ with different current densities 
Table I. The composition of the electrolyte bath used to deposit Sn on brass

\begin{tabular}{|c|c|c|c|c|c|}
\hline $\begin{array}{l}\text { Stannous } \\
\text { sulfate }(\mathrm{g} / \mathrm{l})\end{array}$ & $\begin{array}{c}\text { Sulfuric } \\
\text { acid }(\mathrm{ml} / \mathrm{l})\end{array}$ & $\begin{array}{l}\text { Cresolsulfonic } \\
\text { acid (ml/l) }\end{array}$ & Gelatin (g/l) & $B$-Naphthol (g/l) & Hydroquinone (g/l) \\
\hline 30 & 50 & 30.8 & 0.5 & 0.25 & 0.25 \\
\hline
\end{tabular}

The composition is given for 11 of electrolyte.

$\left(5-30 \mathrm{~mA} / \mathrm{cm}^{2}\right)$ and were subjected to either isothermal aging at $50^{\circ} \mathrm{C}$ or $150^{\circ} \mathrm{C}$ for $48 \mathrm{~h}$ or thermal cycling between $-25^{\circ} \mathrm{C}$ and $85^{\circ} \mathrm{C}$ for 100 cycles. Average heating and cooling rates during thermal cycling were $\sim 2^{\circ} \mathrm{C} / \mathrm{min}$.

Observation of the as-deposited microstructure of the coatings and measurement of whisker density were conducted by use of SEM. The average grain size of the deposit, $l$, was determined by use of the mean linear intercept method, in which $l$ was calculated by dividing the total line length by the number of grain boundaries intercepted. ${ }^{32}$ This value of $l$ can be directly related to the three-dimensional grain diameter, $D$, with a suitable proportionality constant. ${ }^{33}$ However, the reported grain size in the study corresponds to the mean linear intercept length (i.e., $l$ ). Whisker density, defined as number of whiskers per unit area, was calculated by periodic observation of the Sn coatings. For the samples stored under isothermal conditions, whisker density was calculated $7,15,30,60$, and 90 days after deposition. Whisker density reported here is the average whisker density calculated from at least 30 different regions covering a total area of $1 \mathrm{~cm}^{2}$.

X-ray peak profiles were obtained from the as-deposited films by use of x-ray diffraction (XRD) with a $\mathrm{Cu} \mathrm{K}_{\alpha}$ source. The XRD scans were obtained with incidence angle $(2 \theta)$ varying from $25-90^{\circ}$. XRD with a rotating stage and an area detector was used to construct the pole figures. Preferred crystallographic texture was estimated from x-ray peak intensities and was confirmed by measurement of pole figures. The distribution of substrate elements ( $\mathrm{Cu}$ and $\mathrm{Zn})$ in the $\mathrm{Sn}$ deposit was studied by electron probe micro-analysis (Jeol JXA-8530F-EPMA) operated at an accelerating voltage of $15 \mathrm{kV}$. Atomic concentration maps of $\mathrm{Cu}, \mathrm{Zn}$, and $\mathrm{Sn}$ were generated by scanning an electron beam over the sample, with a dwell time of $10 \mathrm{~ms}$ at each grid point.

\section{RESULTS}

\section{Microstructure and Grain size}

Cathode current efficiency (CCE), $\xi$, is often used to describe the efficiency of utilization of current to deposit the metal ions from solution on to a cathode surface and, hence, it can be used as an indicator of the rate of deposition at a given current density: the higher the CCE, faster the rate of deposition. $\xi$ is defined as the ratio of amount of metal deposited on the cathode to that expected theoretically from Faraday's law, and can be calculated as follows: ${ }^{31}$

$$
\xi(\%)=\frac{W}{W_{\text {th }}} \times 100,
$$

where $W$ is actual weight of the deposit (calculated by use of the mass difference method) and $W_{\text {th }}$ is theoretical weight of the deposit given as follows (Faraday's law):

$$
W_{\mathrm{th}}=\frac{M I t}{n F},
$$

where $M$ is the molar weight of the metal, $I$ is the current, $t$ is the total deposition time, $n$ is the number of electrons taking part in the reduction, and $F$ is Faraday's constant, equal to 96,485 .

Figure 1 shows variation of cathode current efficiency with the electrodeposition process conditions used in this study. As shown in Fig. 1, $\xi$ generally increased with increasing deposition (substrate) temperature. It also increased with current density at low current densities and decreased at high current densities. Because the kinetics and ionic activation are high at high temperatures, the increase in $\xi$ with temperature is expected. At higher current densities, the decreasing trend in $\xi$ can be attributed to adsorption of $\mathrm{H}^{+}$ions from the bath on to the cathode surface where they combine and evolve as $\mathrm{H}_{2}$; effervescence of $\mathrm{H}_{2}$ gas was observed as formation of dimples on the substrate surface.

Figure 2 shows representative micrographs of a few of the as-deposited coatings obtained by use of different combinations of current density and bath temperature. The process conditions used for electrodeposition clearly affected the grain size and surface morphology of the Sn coatings. Bright deposits with smooth surfaces were obtained at high temperatures. At low temperatures, the surface morphology of the deposit became progressively rougher with increasing current density. The current density did not, however, noticeably affect surface morphology at the higher deposition temperatures. However, the coatings deposited with high current densities, especially at high temperatures, were slightly less porous because of the increased $\mathrm{CCE}$ and, hence, less $\mathrm{H}_{2}$ evolution at cathode. Careful observation of Fig. 2 also reveals that the fraction of equiaxed grains was high if the electrodeposition was conducted at high temperatures. 


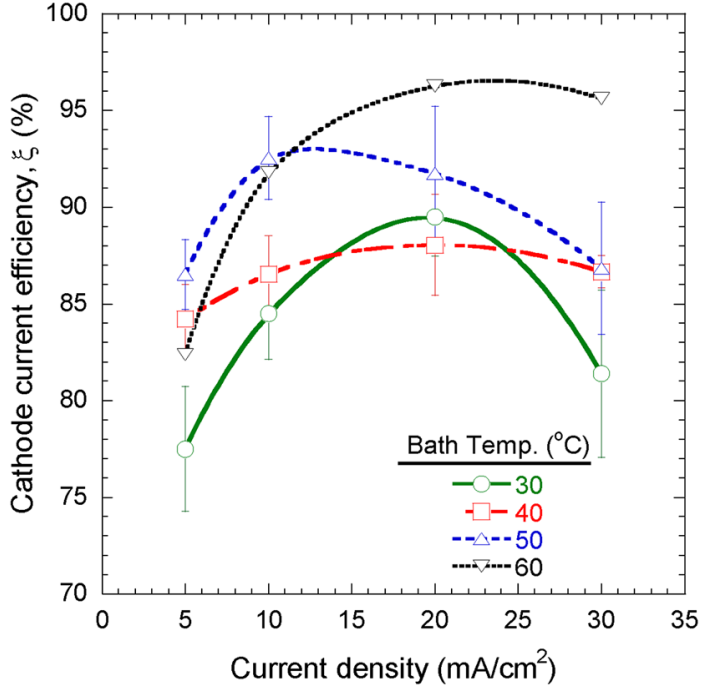

Fig. 1. Variation of cathode current efficiency with current density for the different electrolyte bath temperatures used in this study.
Figure 3 shows the variation of grain size as a function of electrolyte bath temperature, given in terms of homologous temperature relative to the melting temperature of $\mathrm{Sn}$, and the current density. It should be noted that plane curve fitting was conducted by use of non-linear surface fitting, with Origin software. The contour plot shown in Fig. 3 was drawn by using the surface fitted data obtained. As shown in Fig. 3, the average grain size of the Sn deposit increased monotonically with both current density and bath (or substrate) temperature such that the smallest grain size (size $\sim 1 \mu \mathrm{m}$ ) was obtained at the lowest bath temperature $\left(30^{\circ} \mathrm{C}\right)$ and the smallest current density $\left(5 \mathrm{~mA} / \mathrm{cm}^{2}\right)$ whereas the largest grain size (size $\sim 2.8 \mu \mathrm{m}$ ) was achieved at the highest bath temperature $\left(60^{\circ} \mathrm{C}\right)$ and the largest current density $\left(30 \mathrm{~mA} / \mathrm{cm}^{2}\right)$. It is generally believed that the grain size of a coating should decrease with increasing current density. ${ }^{34}$ This decrease in grain size with increasing current density is often related to the increase in the rate of
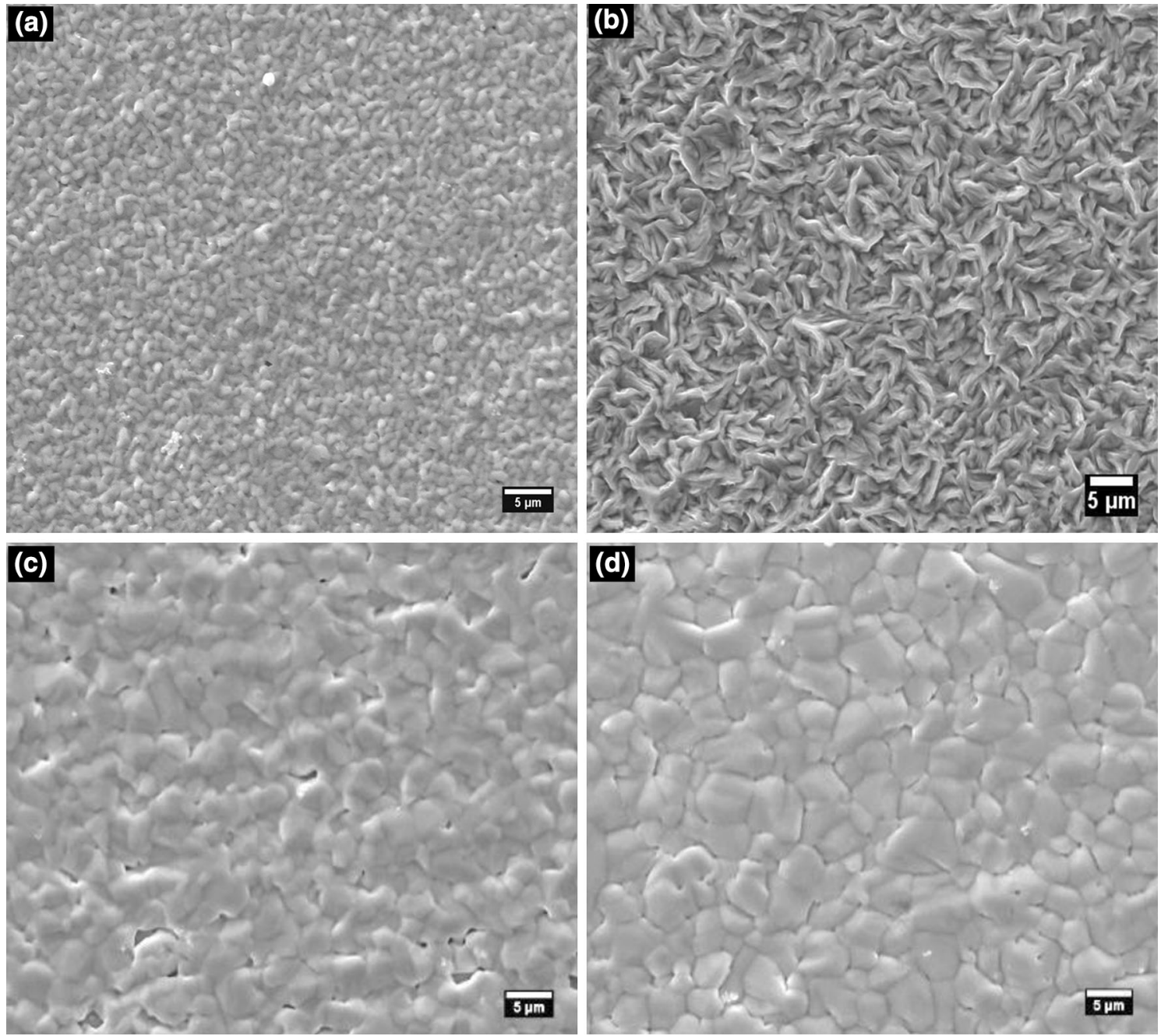

Fig. 2. As-deposited microstructure of the Sn deposits: (a) $30^{\circ} \mathrm{C}, 5 \mathrm{~mA} / \mathrm{cm}^{2}$ (b) $30^{\circ} \mathrm{C}, 30 \mathrm{~mA} / \mathrm{cm}^{2}$ (c) $60^{\circ} \mathrm{C}, 5 \mathrm{~mA} / \mathrm{cm}^{2}$ (d) $60^{\circ} \mathrm{C}, 20 \mathrm{~mA} / \mathrm{cm}^{2}$. 


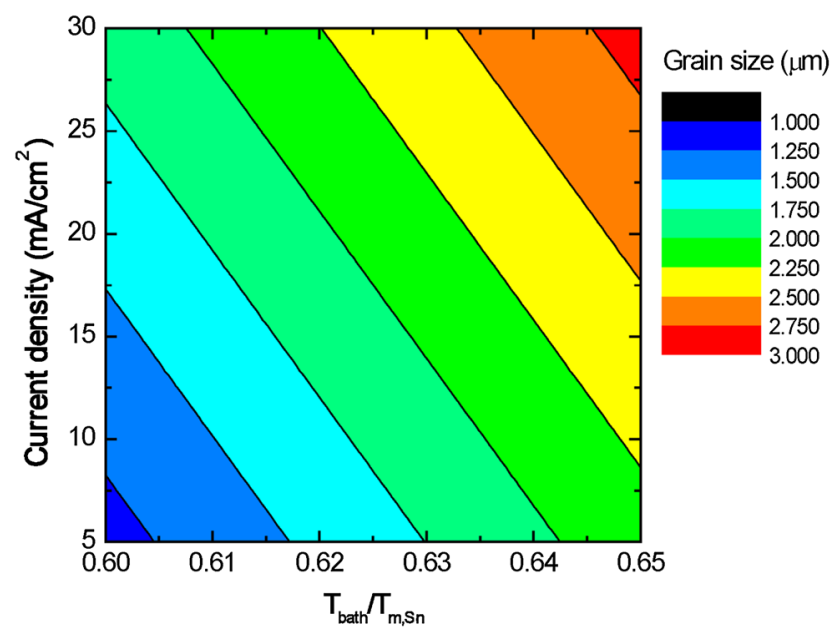

Fig. 3. Variation of average grain size, measured as mean linear intercept length, with current density and electrolyte bath (or substrate) temperature. The electrolyte bath temperature is normalized to the melting temperature of the deposit (i.e., Sn).

nucleation. However, reports stating otherwise are also available; in these the increase in grain size is attributed to reduced metal ion flux at the substrate-electrolyte interface. ${ }^{35,36}$ As will be discussed in subsequent sections, the latter seems to be true in this study. The increase in average grain size with increasing current density is consistent with earlier reports on electrodeposited Sn coatings. ${ }^{37-39}$

It is well established that average grain size in the deposit increases with substrate temperature because of increased diffusivity of atoms which scales with the homologous temperature, $T / T_{\mathrm{m}}$, where $T_{\mathrm{m}}$ is the melting temperature of $\mathrm{Sn}$. Sn has very low melting point $\left(505^{\circ} \mathrm{K}\right)$ and even room temperature $\left(\sim 0.6 T_{\mathrm{m}}\right)$ deposition can be regarded as high-temperature deposition.

\section{Crystallographic Texture of Coatings}

Figure 4 shows the x-ray peak profiles of the Sn deposits obtained within (a maximum of) $24 \mathrm{~h}$ after electrodeposition. Except for a few conditions, all $\mathrm{x}$-ray peak profiles of the coatings contain intense peaks for a particular orientation, indicating preferred crystallographic orientation for specific combinations of deposition temperature and current density. However, a few electrodeposition processing conditions produced two equally strong peaks, for example the $40^{\circ} \mathrm{C}$ and $5 \mathrm{~mA} / \mathrm{cm}^{2}$ combination and the $50^{\circ} \mathrm{C}$ and $5 \mathrm{~mA} / \mathrm{cm}^{2}$ combination, whereas a few also resulted in several minor crystallographic planes, for example the $60^{\circ} \mathrm{C}$ and $5 \mathrm{~mA} / \mathrm{cm}^{2}$ combination.

Figure 5 summarizes the information provided in Fig. 4 by schematically showing the variation of the dominant crystallographic orientations as functions of electrolyte bath temperature and current density. The open star symbol in Fig. 5 indicates the presence of several minor orientations with a dominant orientation, denoted as a filled (or solid) circle. Figure 5 clearly reveals the following:

1 At any electrolyte bath temperature, the crystallographic texture obtained by use of a high current density had lower Miller indices (i.e., higher inter-planar spacing) than that obtained by use of a low current density. For example, at $30^{\circ} \mathrm{C}$ the crystallographic orientation changed from (220) at $30 \mathrm{~mA} / \mathrm{cm}^{2}$ to $(420)$ at $5 \mathrm{~mA} / \mathrm{cm}^{2}$. At higher temperatures a transition from (200) at $30 \mathrm{~mA} / \mathrm{cm}^{2}$ to $(211)$ at $5 \mathrm{~mA} / \mathrm{cm}^{2}$ occurred. As a rule of thumb, it can be concluded that the higher the deposition rate the greater the growth of low Miller index planes, i.e. planes with larger interplanar spacing (or d-spacing).

2 At any current density, increasing the electrolyte bath temperature led to preferred growth of lowMiller index planes. For example, at $30 \mathrm{~mA} / \mathrm{cm}^{2}$, a transition from $(220)$ at $30^{\circ} \mathrm{C}$ to $(200)$ at 50 and $60^{\circ} \mathrm{C}$ occurred. Similarly, at the lower current density of $5 \mathrm{~mA} / \mathrm{cm}^{2}$, a transition from (420) at $30^{\circ} \mathrm{C}$ to $(211)$ at $60^{\circ} \mathrm{C}$ occurred. Again, as a rule of thumb, higher was the deposition temperature the greater the growth of planes with larger interplanar spacing.

3 The Sn deposits were highly textured if electrodeposition was conducted at high current density. As the current density decreased, several minor orientations, for example (321), (411), also appeared, especially if the electrolyte bath temperature was high. The observed loss of highly textured deposition at high temperature and low current density can be attributed to the nucleation of planes of multiple orientations, which becomes favorable at high deposition temperatures and which may lead to stable growth of differently oriented planes especially if deposition was conducted slowly (i.e., at low current density).

In summary, electrodeposition Sn on brass at high current density and high temperature resulted in deposits containing predominantly low-Miller index planes whereas a combination of low current density and low temperature produced Sn deposits with high Miller index planes. Moreover, electrodeposition using high current density at low temperatures led to formation of highly textured coatings, whereas several minor crystallographic textures were present in Sn coatings deposited using low current density at high temperatures.

\section{Whisker Density Evaluation}

Figure 6 shows a few representative SEM micrographs of Sn coatings deposited by use of a variety of electrodeposition conditions and exposed to different thermal conditions for 1 month. Figure 6 clearly 

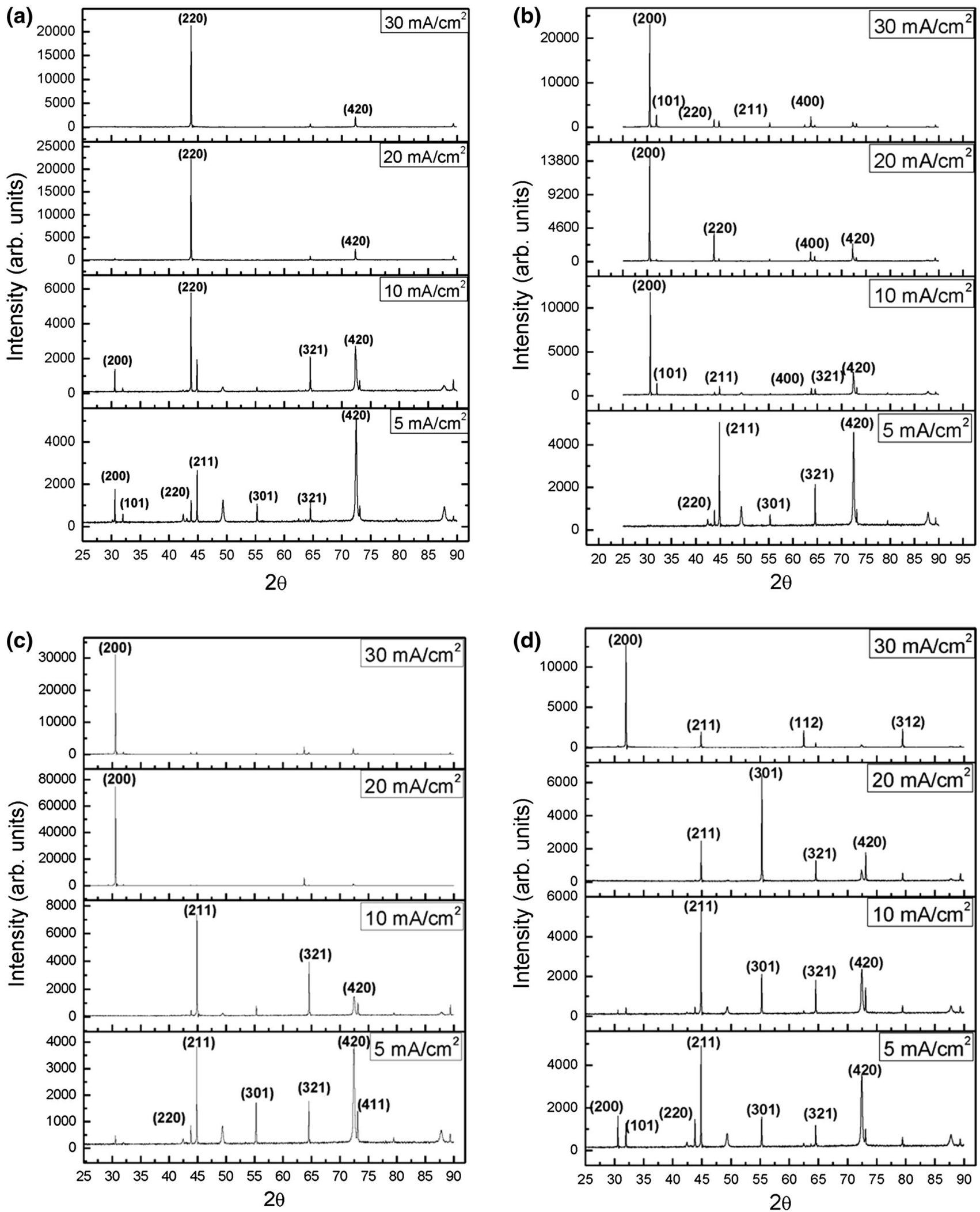

Fig. 4. X-ray peak profiles of $\mathrm{Sn}$ coatings prepared by use of different current densities at electrolyte bath temperatures of: (a) $30^{\circ} \mathrm{C}$ (b) $40^{\circ} \mathrm{C}$ (c) $50^{\circ} \mathrm{C}$ and (d) $60^{\circ} \mathrm{C}$. The value of the current density is given at the top right of each plot. 
shows growth of several filament-type whiskers protruding from the Sn coating. A few of the whiskers are straight whereas a few are kinked and

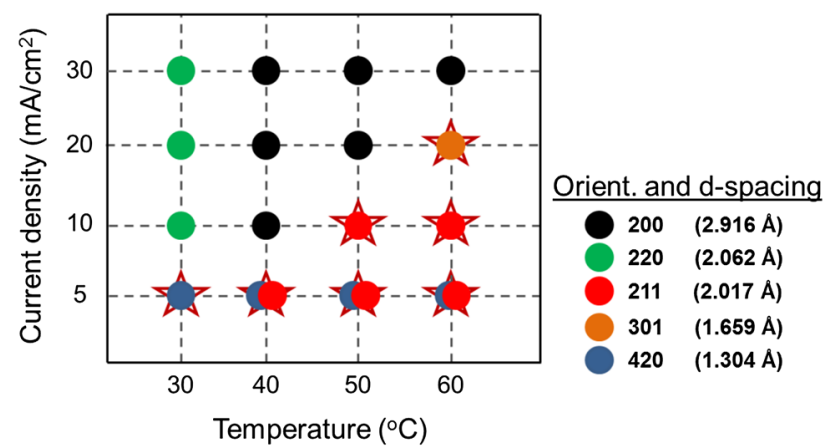

Fig. 5. Summary of the most dominant orientation observed in the $\mathrm{Sn}$ deposits. Overlapping circles shows equally dominant orientations whereas the open star shows the conditions where multiple minor orientations were observed. The terms Orinet. and d-spacing represent crystallographic orientation and inter-planar spacing, respectively. rotated. Hence, growth of regular Sn whiskers, as reported previously, ${ }^{40,41}$ was observed in this study.

Qualitative comparison of Fig. 6a and b clearly reveals that whiskers on Sn coatings deposited with higher current density were much longer than for the coating deposited at low current density. Comparison of Fig. $6 \mathrm{~b}$ and c, however, reveals that although fewer whiskers grew from Sn coatings deposited at higher electrolyte bath temperature, the length and morphology of several whiskers growing from these two deposits were similar. Finally, comparison of Fig. 6c and d clearly shows that isothermal aging at moderately high temperature led to formation of a large number of whiskers with a wide range of lengths. Interestingly, unlike the sample stored at room temperature, few whiskers remained fully straight for Sn coatings subjected to aging at $50^{\circ} \mathrm{C}$. In conclusion, Fig. 6 suggests that the Sn coatings deposited on brass at low temperature using small current density were less prone to short-circuiting via whiskering, if they were stored at low temperatures.
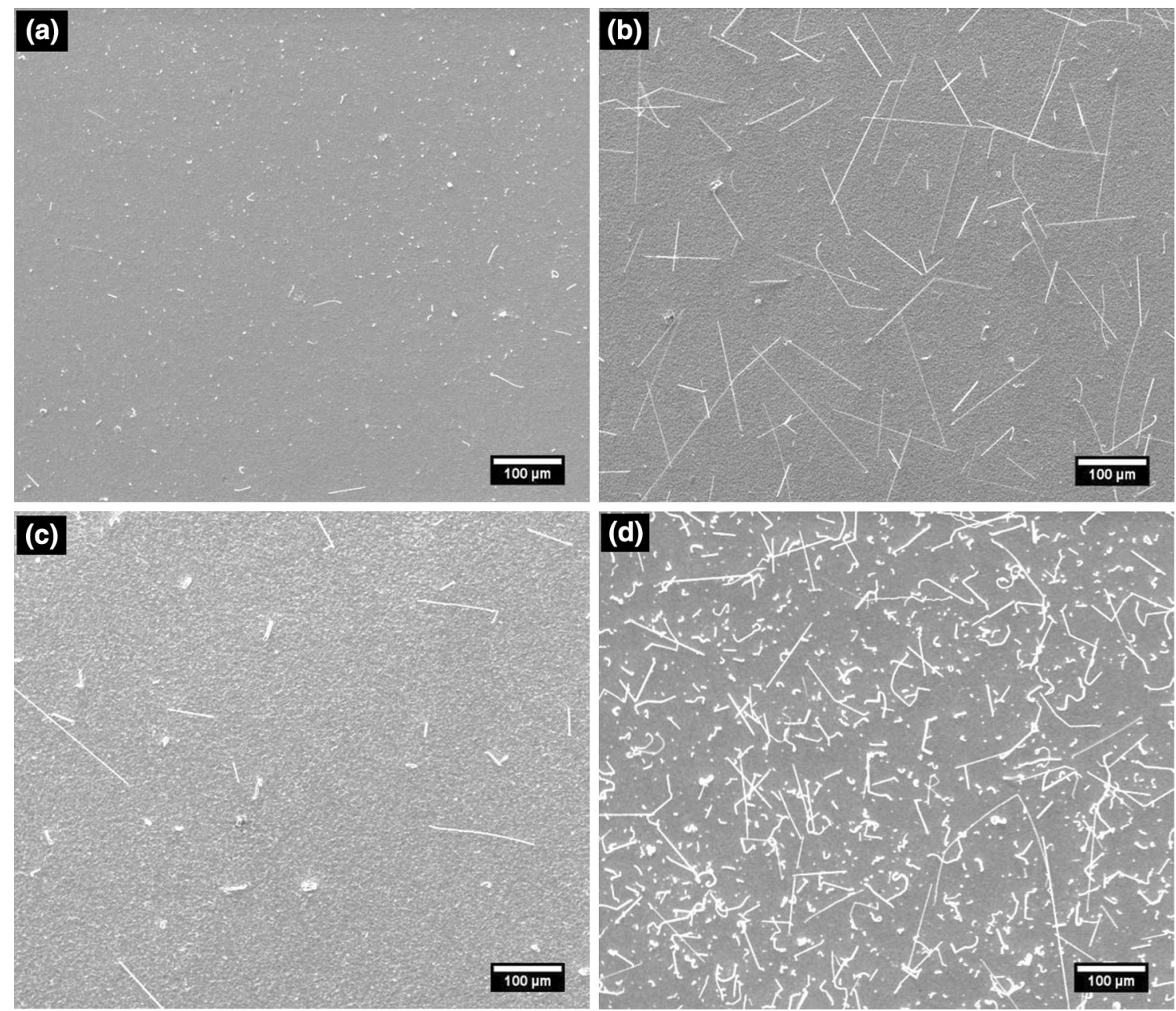

Fig. 6. Whisker growth on Sn coatings 1 month after electroplating by use of different process conditions: (a) $30^{\circ} \mathrm{C}, 5 \mathrm{~mA} / \mathrm{cm}^{2}(\mathrm{~b}) 30^{\circ} \mathrm{C}, 30 \mathrm{~mA} /$ $\mathrm{cm}^{2}$ (c) $40^{\circ} \mathrm{C}, 30 \mathrm{~mA} / \mathrm{cm}^{2}$ (d) $40^{\circ} \mathrm{C}, 30 \mathrm{~mA} / \mathrm{cm}^{2}$. The samples shown in (a), (b) and (c) were subjected to room temperature aging whereas the sample shown in (d) was isothermally aged at $50^{\circ} \mathrm{C}$. 


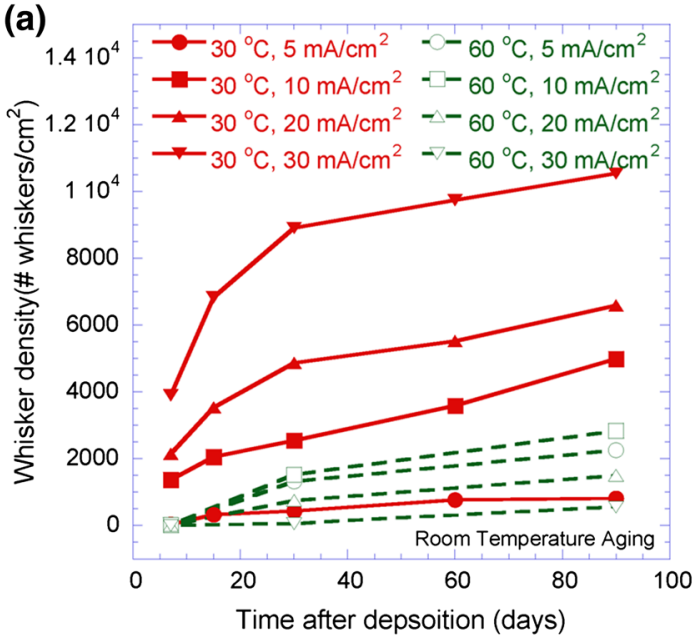

(b)

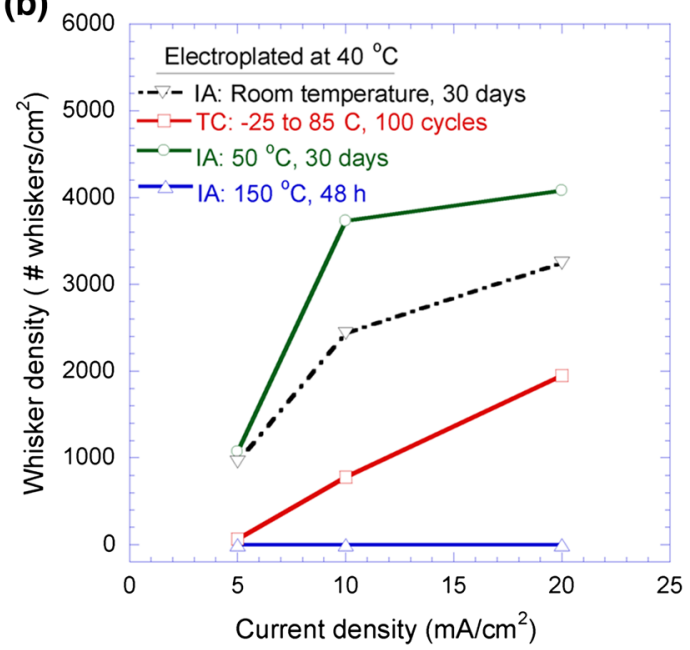

Fig. 7. Whisker density observed for a variety of $\mathrm{Sn}$ coatings: (a) stored at room temperature, and (b) deposited at $40^{\circ} \mathrm{C}$ using different current densities then exposed to different storage conditions. IA Isothermal aging, TC Thermal cycling.

Figure 7 shows, quantitatively, the evolution in the whisker density, measured as the total number of whiskers per unit area, as a function of the environmental conditions under which the Sn coatings were stored. As shown in Fig. 7a, whisker density on samples deposited at low electrolyte bath temperature was generally higher, although with one exception, than on those deposited at high electrolyte bath temperature. For Sn coatings deposited at low temperature, samples deposited at high current density were more prone to whisker formation. Because, as shown in Fig. 4a, the dominant orientation (gradually) changed from (420) to (220) for Sn coatings deposited at $30^{\circ} \mathrm{C}$ with increasing current density, it can be concluded that a (420) or higher Miller index plane is less prone to whiskering than a (220) or lower Miller index plane. Although the effect of current density on whiskering of Sn coatings deposited at $60^{\circ} \mathrm{C}$ was not as prominent as that for coatings deposited at low temperatures, a few very important

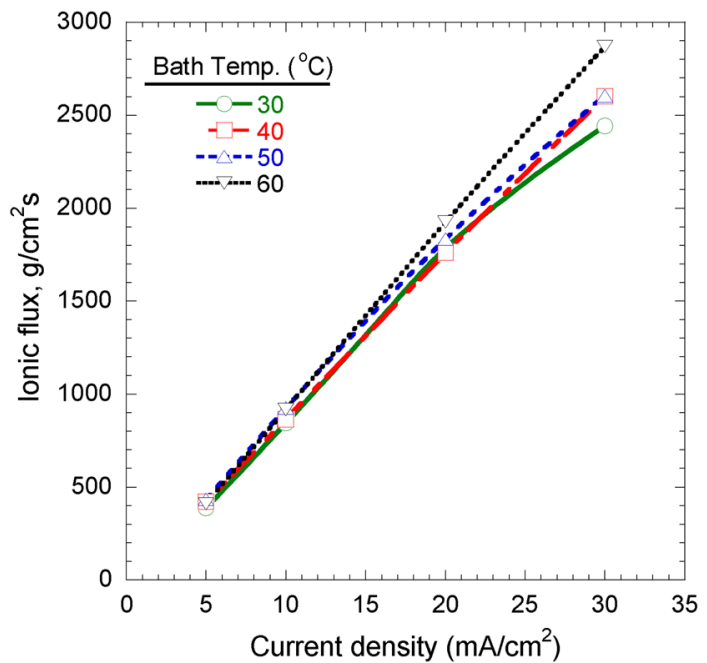

Fig. 8. Variation of ionic flux as a function of current density at different electrolyte bath temperatures.

trends are apparent from the results obtained for coatings deposited at $60^{\circ} \mathrm{C}$, as shown in Figs. 4 and 7:

1 The amount of whisker formation increased slightly from $5 \mathrm{~mA} / \mathrm{cm}^{2}$ to $10 \mathrm{~mA} / \mathrm{cm}^{2}$ (Fig. 7a), and a corresponding decrease in the intensity of (420) and an increase in that of (211) was observed (Fig. 4). This is consistent with the above conclusion that the (420) texture suppresses whiskering.

2 The amount of whisker formation then drastically decreased from $10 \mathrm{~mA} / \mathrm{cm}^{2}$ to $20 \mathrm{~mA} / \mathrm{cm}^{2}$ and then again slightly from $20 \mathrm{~mA} / \mathrm{cm}^{2}$ to $30 \mathrm{~mA} /$ $\mathrm{cm}^{2}$, and a simultaneous decrease in the (211) texture was observed, with an increase in either (301) or (200) texture.

On the basis of these two observations, it can concluded that (211) and (420) are the most and the least, respectively, suitable crystallographic textures for whisker formation. It should also be noted that the grain size of Sn coatings increased monotonically with current density at any electrolyte bath temperature (Fig. 3); however, a monotonic effect of current density on amount of whisker formation was not always observed. Therefore, for the Sn coatings tested in this study, the effect of grain size on whisker formation does not seem to be as dominant as that of crystallographic texture. This is mainly because, in this study, the grain size of the Sn coatings, at any temperature, differed by less than a factor of 2 , which is not large enough to have a significant effect on whiskering. For example for deposition temperatures of $30^{\circ} \mathrm{C}, 40^{\circ} \mathrm{C}$, $50^{\circ} \mathrm{C}$, and $60^{\circ} \mathrm{C}$, grain size increased from $0.96 \mu \mathrm{m}$ to $1.63 \mu \mathrm{m}, 1.65 \mu \mathrm{m}$ to $2.28 \mu \mathrm{m}, 1.8 \mu \mathrm{m}$ to $2.4 \mu \mathrm{m}$, and $2.06 \mu \mathrm{m}$ to $2.8 \mu \mathrm{m}$, respectively, with current density. As reported by Kakeshita et al., ${ }^{42}$ grain size should usually be different by at least several factors to an order of magnitude if a noticeable effect of grain size on whiskering is to be observed. 

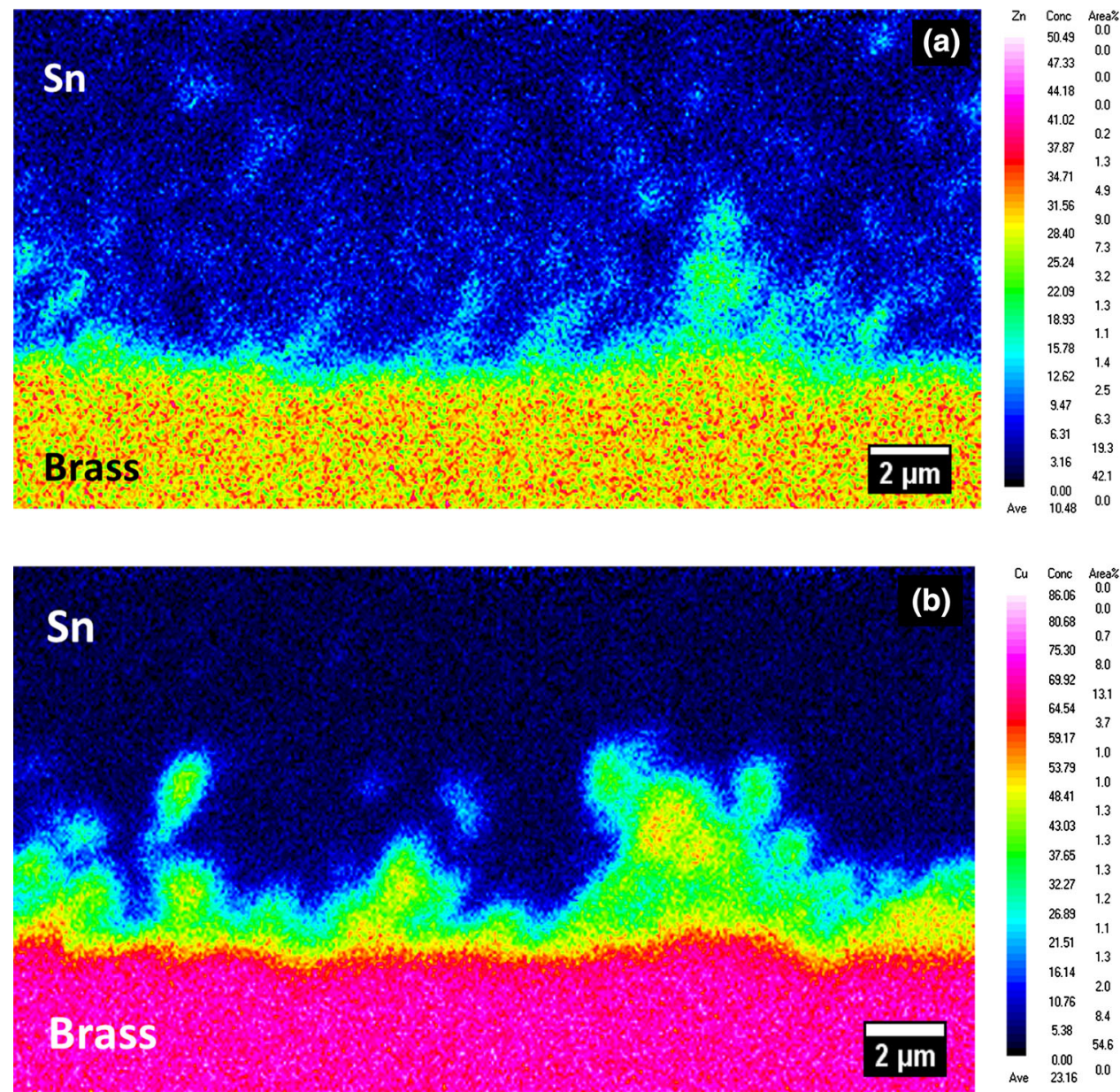

Fig. 9. Atomic concentration maps of (a) $\mathrm{Zn}$ and (b) Cu obtained by electron probe micro-analysis (EPMA).

Figure $7 \mathrm{~b}$ shows the effect of storage under different storage (or service) conditions on whisker density for Sn coatings deposited at $40^{\circ} \mathrm{C}$ by use of different current densities. Irrespective of the current density used for electrodeposition, the rate of whisker growth was higher for samples subjected to isothermal aging (IA) at $50^{\circ} \mathrm{C}$ for 30 days than for samples stored at room temperature; no whisker growth was observed for $\mathrm{Sn}$ coatings isothermally aged at $150^{\circ} \mathrm{C}$ for $48 \mathrm{~h}$. Fewer whiskers grew on Sn coatings thermally cycled (TC) from $-25^{\circ} \mathrm{C}$ to $85^{\circ} \mathrm{C}$ for 100 cycles than on samples stored at the room temperature for 30 days. Figure $7 \mathrm{~b}$ also shows that the amount of whisker formation on Sn coatings deposited at high current density was usually higher than for coatings deposited at low current density. This is similar to observations for samples electroplated at $30^{\circ} \mathrm{C}$ (Fig. 7a) and similar conclusion about the effect of crystallographic texture on whiskering can be deduced. Here also, samples deposited at $40^{\circ} \mathrm{C}$ using $5 \mathrm{~mA} / \mathrm{cm}^{2}$ current density had a strong (420) texture (along with the (211) texture) (Fig. 4) and the lowest whisker density of all the samples shown in Fig. 7b. Furthermore, as shown in Fig. 4, the volume fractions of (420) and (200) grains in the Sn coatings decreased and increased, respectively, with increasing current density, which corresponded to an increase in whisker density (Fig. 7b). It can, therefore, be concluded that the (200) orientation also favors whisker growth.

It is interesting to note that the (200) orientation of $\mathrm{Sn}$ coatings deposited at $40^{\circ} \mathrm{C}$ enhanced whisker growth (Fig. 7b) whereas for samples deposited at $60^{\circ} \mathrm{C}$ with the (200) texture the density of whiskers was lower than for samples with the (211) texture (Fig. 7a). This variation can be attributed to the combined effect of reduction of stress in the coatings and probably increased grain size when deposition is conducted at high temperature.

\section{DISCUSSION}

\section{Effect of Process conditions on Microstruc- ture and Grain Size}

Electrodeposition process conditions affect nucleation and growth ${ }^{43}$ and hence control grain shape and size, texture, and residual stress in the deposit. The ratio of electrolyte bath (or substrate) temperature, $T_{\text {bath }}$, to the melting temperature of $\mathrm{Sn}$, $T_{\mathrm{m}, \mathrm{Sn}}$, is an important property which governs the 


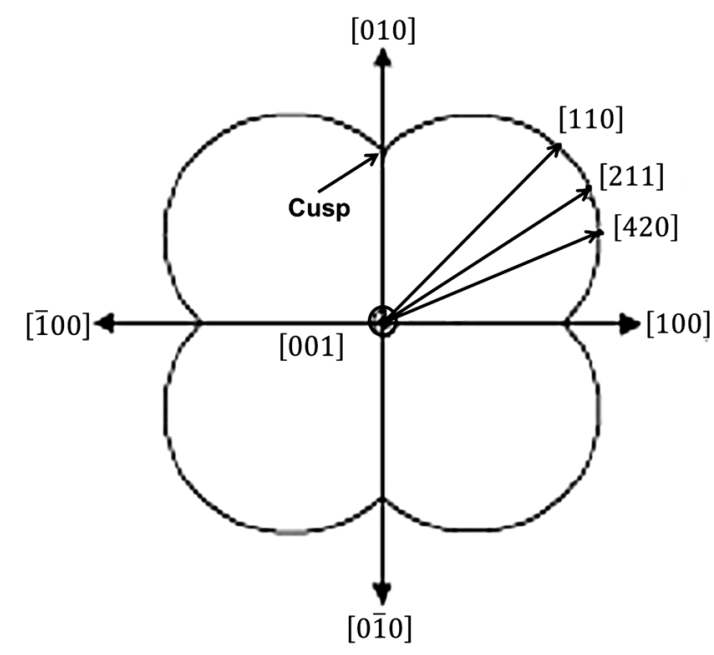

Fig. 10. Wolf's plot showing the relative positions of the different planes. The arrows show the direction normal to the corresponding planes. The length of an arrow shows the surface energy of the corresponding plane. The plot is derived from Refs. 53 and 54.

evolution of microstructure in thin film growth; $;^{44,45}$ this is also corroborated by Fig. 3, which shows a monotonic increase in grain size with increasing the $T_{\mathrm{bath}} / T_{\mathrm{m}, \mathrm{Sn}}$. Surface and grain boundary diffusivity increase with substrate temperature and adatoms have extra energy and so can be rearranged from high-energy configurations to low-energy configurations producing deposits with larger grain sizes and less residual stress. Reduction in grain boundary free energy is the driving force for grain growth, with larger grains growing at the expense of the smaller grains. Although the substrate temperatures $\left(30-60^{\circ} \mathrm{C}\right)$ used in this study did not differ substantially, and corresponded to a variation of homologous temperature from 0.60 to 0.65 , a significant variation in the grain morphology (and crystallographic texture), along with marginal increase in grain size was observed; this suggests that electrodeposition of Sn on brass is highly sensitive to the temperature of the electrolyte bath.

Ionic flux, defined as the rate of deposition per unit area of the sample, can be calculated by multiplying the current density and the cathode current efficiency. Figure 8 shows the variation of ionic flux as function of the current density for different electrolyte bath temperatures. As shown in Fig. 8, the rate of deposition of Sn increased monotonically with current density. Therefore, adsorption of metal ions on the substrate surface per unit time increased with current density, finally leading to enhanced rate of island nucleation and growth. Because, as shown in Fig. 3, grain size increased monotonically with the current density, it seems that growth of Sn grains superseded the rate of nucleation because of the increase in the rate of deposition. This may be attributed to the low melting temperature of Sn, compared with which all the deposition temperatures used in this study qualified as high temperatures $\left(T_{\mathrm{m}}>0.6\right)$ resulting in a high growth rate.
As shown in Fig. 2, samples deposited at low temperature with a high current density had very rough, faceted surface (Fig. 2b) compared with samples deposited at either at low current density (for example $30^{\circ} \mathrm{C}, 5 \mathrm{~mA} / \mathrm{cm}^{2}$, Fig. 2a) or at high electrolyte bath temperatures (for example $60^{\circ} \mathrm{C}$, Fig. $2 \mathrm{c}$ and d). This can be explained as follows. At low deposition temperatures, adatoms do not have sufficient energy for surface diffusion. Therefore, the grain boundaries formed during coalescence of Sn islands do not have high mobility. Under such conditions, if deposition is conducted at high rates, for example at high current density, the island growth process can be quicker than the rate of surface and grain boundary self-diffusion. In such cases, the built up stress generated during deposition, arising mainly because of coalescence of growing Sn islands, will not be quickly relieved. The built up stress may cause out-of-plane reorientation of the Sn grains, producing very rough coatings, as shown in Fig. $2 \mathrm{~b}$.

\section{Texture and Whisker Formation}

One mechanism proposed for generation of compressive stress in Sn deposited on brass is diffusion of $\mathrm{Zn}$ and $\mathrm{Cu}$ from the substrate into the Sn coating. Diffusivity of $\mathrm{Zn}$ in brass (and in $\mathrm{Sn}$ ) is higher than that of $\mathrm{Cu},{ }^{46}$ and both $\mathrm{Zn}$ and $\mathrm{Cu}$ diffuse into $\mathrm{Sn}$ via interstitial diffusion ${ }^{46,47}$ and along the $\mathrm{Sn}$ grain boundaries. ${ }^{21}$ This discussion is further illustrated by Fig. 9, which shows the atomic concentration map for $\mathrm{Zn}$ and $\mathrm{Cu}$ atoms diffusing into Sn coating deposited on a brass substrate. Comparison of Fig. 9a and b clearly shows that $\mathrm{Zn}$ diffuses rapidly and very deeply into Sn. Furthermore, the elongated band-like features near the interface between $\mathrm{Sn}$ and the substrate indicate that diffusion of $\mathrm{Zn}$ occurred predominantly along the grain boundaries. Zn atoms diffusing along grain boundaries may also react with tin oxide formed at the surface of the coating and along grain boundaries to form zinc oxide which is more stable oxide than tin oxide. ${ }^{48}$ Formation of $\mathrm{ZnO}$ at $\mathrm{Sn}$ grain boundaries has recently been confirmed in an x-ray photoelectron spectroscopy (XPS)-based study. ${ }^{49}$ Interestingly, Sn atoms released by this reaction may also provide additional flux to form whiskers. ${ }^{50}$ This is similar to accelerated growth of tin whiskers in the presence of rare earth elements. ${ }^{50,51}$ Besides adding to the flux of $\mathrm{Sn}$ atoms to whiskers, formation $\mathrm{ZnO}$ along the grain boundaries produces compressive stress in the surrounding grains and $\mathrm{ZnO}$-induced grain boundary pinning restricts the chances of residual stress relaxation by recrystallization, grain growth, or Coble creep. Because diffusion of $\mathrm{Zn}$ in $\mathrm{Sn}$ is also via the grain boundary, the grain size and the nature of the grain boundary, which are also dependent on the orientation of the neighboring grains, will substantially affect the stress state in the Sn and hence whisker growth. However, as shown in Fig. 7, whisker density increased substantially if film 
deposition was conducted at high current density, and if the grain size of the sample was large (Fig. 3). This is contrary to effect of grain size on diffusion of Zn. This may be, as already mentioned, because in our experiments the increase in grain size was only marginal; however, the crystallographic texture changed substantially with current density at all deposition temperatures. One interesting implication of the above discussion on the effect of presence of $\mathrm{Zn}$ in the substrate on whisker formation is that pure $\mathrm{Cu}$ should be preferred to slow down the whiskering process (Supplemental Material 1).

Because $\beta$-Sn has a highly anisotropic bodycentered tetragonal structure, the rate of diffusion of $\mathrm{Cu}$ and $\mathrm{Zn}$ will depend on grain boundary orientation. Therefore, Zn may preferentially diffuse along grain boundaries which are highly disorientated with adjacent grains and large compressive stress will build up in the surrounding grains. Therefore, crystallographic texture is the dominant factor affecting diffusion of $\mathrm{Zn}$ and stress generation. Stress may also arise as a result of elastic or thermal expansion mismatch between neighboring grains of different orientations and, as will be explained later, because of different surface energy (or surface tension) of neighboring grains. Although both stress generation and diffusion (or mass transport) are important contributors to whisker growth, their relative importance is unclear.

It should be noted that XRD-based macro-texture measurement provides information on a global scale only, and local site-specific information about crystal orientation and stress state, which may play an important role in the whisker growth, cannot be obtained role from such measurements. Electron backscattered diffraction (EBSD) maps of individual grains can capture this local information but, because of the lack of very flat and specular surfaces of electro-deposited Sn coatings, information from many grains is often lost. Furthermore, there are contradictory results in the literature on the nature of grain orientation of whisker grains and their surrounding adjacent grains. Frye et al. ${ }^{29}$ observed that whisker grains do not have any consistent crystallographic relationship with their adjacent surrounding grains whereas Sarobol et al. ${ }^{52}$ conducted a study using synchrotron micro x-ray diffraction and reported that whisker grains were always highly misoriented compared with the surrounding grains. Therefore, a detailed study of the relative effects of local and global configurations of the grains on whiskering is warranted. In such circumstances, this study, which provides a consistent relationship between macro-texture and extent of whisker growth, not only suggests the importance of the dominant (and second most dominant) texture of the coating on whiskering but may also bridge the gap between conflicting observations based on the effect of micro-texture on whiskering, as mentioned above.
Electrodeposition at high temperature leads to deposition of coatings with minimum surface energy. As shown in Fig. 10, Wolf's surface free energy plot for $\beta$-Sn ${ }^{53,54}$ shows that the (100) planes have the minimum surface free energy and the (110) planes have the highest surface energy. Increasing substrate temperature (and current density) should lead to preferential growth on the (100) plane, minimizing the surface energy of the deposit. However, for $\beta$-Sn, which has body centered tetragonal structure, (100) is the forbidden reflections as the sum of the Miller indices (i.e., $h+k+l$ ) is an odd number. Hence, they appear as higher order reflections in XRD, for example (200) and (220). In absence of definite data on (200) and (220) planes, the ranking of these planes in terms of surface energy can be conducted on the basis of the relationships between the (100) and (110) planes, respectively. Hence, deposition at high temperature should produce coatings with (200) texture, as consistently observed in this study (Figs. 4 and 5, high current density). In contrast, the (220) texture was predominant at low temperature. Hence, coatings with (220) planes will have high surface energy leading to large surface tension, and hence compressive stress inside the coating, compared with coatings with (200) planes. This explains the greater whiskering for the (220) coating than for the (200) coating (Fig. 7). Furthermore, on the basis of the experimental results obtained in this study, the surface energy of (420) planes should be lower than that of (211) and (220) planes, because the whisker density for the former was less than for the latter; this is consistent with the analysis conducted using Wolf's plot, as shown in Fig. 10.

When a compressive stress gradient is generated between a highly compressed region and a whisker root, diffusion of Sn occurs leading to continuous growth of the whisker. As consistently observed in this study (Figs. 4 and 7), low Miller index planes, which correspond to large inter-planar spacing, often resulted in greater whisker growth than high Miller index planes. Because lattice diffusion is faster through planes with large inter-planar spacing, direct correspondence between high whisker density and large inter-planar spacing indicates lattice diffusion of $\mathrm{Sn}$ is the dominant mass transfer mechanism responsible for whisker growth in $\mathrm{Sn}$ coatings. Thus, it seems that the grain boundaries are the high stress concentration regions responsible for generation of the force driving whiskering and the grains are the most probable conduits for the mass transfer responsible for the growth of whiskers on Sn coatings on the brass substrate.

As already mentioned, Lal and Moyer ${ }^{24}$ observed (220) planes to be whisker-resistant whereas (321) and (211) planes were whisker-prone. Although this study also reports the (211) plane to be whiskerprone, (220) was not the least whisker-prone crystallographic texture in this study. The (420) plane was observed to be the most whisker-resistant in 
this study. It should be noted that the (420) plane, which was the least whisker prone crystallographic texture in this study, was not observed in study of Lal and Moyer. ${ }^{24}$ Furthermore, it should be noted that their study ${ }^{24}$ involved whiskering on Sn coatings electroplated by use of an MSA bath on oxygenfree annealed $\mathrm{Cu}$ foils with an inter-layer of $\mathrm{Ni} 2 \mu \mathrm{m}$ thick between the $\mathrm{Sn}$ and the substrate. The grains of the MSA coated Sn were well polygonized and their sizes varied from $2.3 \mu \mathrm{m}$ to $13 \mu \mathrm{m}$. Furthermore, the presence of an Ni interlayer can significantly slow diffusion of the substrate atoms $(\mathrm{Cu}$ or $\mathrm{Zn}$ ) into the Sn coating; this also suppresses the growth of $\mathrm{Cu}_{6} \mathrm{Sn}_{5}$, an interfacial IMC credited with increasing the compressive stress in Sn coating. ${ }^{55} \mathrm{In}$ addition, diffusion of $\mathrm{Zn}$ from the brass substrate, as used in this study, into the Sn coating may mechanistically be very different from diffusion of $\mathrm{Cu}$, only, into Sn. Therefore, the different results in this study and in that by Lal and $\mathrm{Moyer}^{24}$ may arise because of the use of different substrates, grain sizes, the interlayer, and the bath chemistry.

\section{Effect of Thermal Treatment on Whisker Formation}

As shown in Figs. 6 and 7b, whisker growth rate was highest for Sn coatings subjected to isothermal aging at $50^{\circ} \mathrm{C}$. This can be attributed to faster diffusion of substrate material into the Sn coating and enhanced pinning of grain boundaries by $\mathrm{ZnO}$ at the elevated temperature; both of these cause more extrusions from the film surface than for samples stored at room temperature. Furthermore, the rate of growth of the $\mathrm{Cu}_{6} \mathrm{Sn}_{5}$ IMC, which has excess vacant sites compared with the $\mathrm{Cu}_{3} \mathrm{Sn} \mathrm{IMC}$, another IMC formed in the $\mathrm{Cu}-\mathrm{Sn}$ system, is much faster at $50^{\circ} \mathrm{C}$ than at room temperature or even at $150^{\circ} \mathrm{C} .^{34}$ Because of the many vacant sites in the $\mathrm{Cu}_{6} \mathrm{Sn}_{5}$ IMC, diffusion of $\mathrm{Cu}$ and $\mathrm{Zn}$ through $\mathrm{Cu}_{6} \mathrm{Sn}_{5}$ is rapid. Therefore, rapid diffusion because of the high temperature and the presence of a relatively poor diffusion barrier in the pathway of the $\mathrm{Zn}$ and $\mathrm{Cu}$ put the Sn coating under more compressive stress. ${ }^{56}$ In addition, as suggested by Boettinger et al., 55 formation of $\mathrm{Cu}_{6} \mathrm{Sn}_{5}$ IMC at the interface of the $\mathrm{Sn}$ and $\mathrm{Cu}$ substrate from the supersaturated $\mathrm{Sn}$ causes a fractional volume change of +0.022 leading to increased compressive stress in the Sn.

Interestingly, no whiskers were observed on coatings subjected to aging at $150^{\circ} \mathrm{C}$ even after $48 \mathrm{~h}$; only a few hillocks were observed. In the $\mathrm{Cu}-\mathrm{Sn}$ system, the $\mathrm{Cu}_{3} \mathrm{Sn}$ intermetallic is more stable above $60^{\circ} \mathrm{C}$ and forms at the interface between the substrate and the $\mathrm{Cu}_{6} \mathrm{Sn}_{5}$ IMC. Because of the lack of vacant sites, $\mathrm{Cu}_{3} \mathrm{Sn}$ acts as an effective barrier to diffusion of $\mathrm{Cu}$ (and $\mathrm{Zn}$ ) from the substrate to $\mathrm{Cu}_{6} \mathrm{Sn}_{5}$ and, subsequently, to the Sn. Therefore, diffusion of $\mathrm{Cu}$ and $\mathrm{Zn}$ into $\mathrm{Sn}$ is retarded and generation of compressive stress is suppressed. In addition, $150^{\circ} \mathrm{C}$ corresponds to $\sim 0.84 T_{\mathrm{m}}$ of $\mathrm{Sn}$, at which stress-relaxation processes such as creep, recovery, and recrystallization, are very rapid. Both of these processes (i.e. retarded compressive stress generation and rapid stress relaxation) finally led to complete elimination of whisker growth at $150^{\circ} \mathrm{C}$.

As shown in Fig. 7b, the whisker density on Sn coatings subjected thermal cycling between $-25^{\circ} \mathrm{C}$ and $85^{\circ} \mathrm{C}$, even after 100 cycles, was less than on those kept at room temperature and $50^{\circ} \mathrm{C}$ for 1 month. Interestingly, the sample exposed to thermal cycling was kept between $-25^{\circ} \mathrm{C}$ and $85^{\circ} \mathrm{C}$ for more than 15 days. The maximum shear strain per cycle was only $5.06 \times 10^{-4}$ owing to the small difference between the values of the CTE $(\alpha)$ of Sn and brass $\left(\alpha_{\mathrm{Sn}}=23.3 \times 10^{-6} / \mathrm{K}, \quad \alpha_{\text {Brass }}=18.7 \times\right.$ $10^{-6} / \mathrm{K}^{57,58}$ ). Therefore, strain imposed on the $\mathrm{Sn}$ coating during thermal cycling can be neglected. Because the $\beta$-Sn is transformed to $\alpha$-Sn at $13^{\circ} \mathrm{C}$, a repeated thermal cycling between $-25^{\circ} \mathrm{C}$ and $85^{\circ} \mathrm{C}$ may cause periodic atomic rearrangement. A crystal structure transformation often reduces the residual stress, thermal cycling across the crystal structure transformation temperature may actually reduce the compressive stress built up in the Sn coatings, finally leading to suppression of whisker growth.

Although a few reports documenting the effects of crystallographic texture and residual stress on whisker growth on Sn coatings are available in the open literature, fundamental understanding of the specifics of the effects of crystallographic orientation on whisker growth has been elusive. This is partly because the effect of crystallographic texture was never isolated from the effects of other factors, for example grain size, coating thickness, bath chemistry, micro-alloying and substrate composition, and thickness. This work fills this gap, first by isolating the effect of crystallographic texture from the other factors by keeping these almost constant while substantially varying crystallographic texture only. Second, this study provides a detailed and systematic process map for selecting an optimum combination of the electrodeposition process conditions, namely temperature and current density, the most easily controlled process conditions, for producing a Sn coating with the desired crystallographic texture. Hence, to the best of the authors' knowledge, this is the first study which clearly indicates how process conditions affect the crystallographic texture of the pure Sn coatings and, consequently, whisker growth.

\section{CONCLUSIONS}

1 Electrodeposition process conditions, namely electrolyte bath temperature and current density, determine the microstructure, grain sizes, and crystallographic texture of Sn coatings. A combination of high deposition temperature and high current density yields smooth deposits with large grains, whereas a combination of low deposition 
temperature and low current density yields Sn coatings with small grains.

2 In general, the crystallographic texture observed at high current density was of lower Miller index (or planes with high inter-planar spacing) than that observed at low current density. Also, increasing the electrolyte bath temperature led to preferred growth of low Miller index planes. Sn deposits electroplated at high current density were highly textured whereas several minor orientations were also present if electrodeposition was conducted at low current density, especially at high temperatures.

3 Crystallographic texture is probably the most important factor affecting whisker growth on Sn coatings on brass. Although grain size has important effects on diffusion and whisker growth, it does not seem to be as important as crystallographic texture; this might be partly because of the small difference (less than a factor of 2) between the grain sizes of the different $\mathrm{Sn}$ coatings deposited in this study. The (220) and (211) orientations are the most favored for whisker growth whereas (420) and (321) are the least favored.

4 Isothermal aging at high temperature $\left(150^{\circ} \mathrm{C}\right)$ completely eliminates whiskering, and thermal cycling across the $\beta$-Sn $/ \alpha$-Sn transitions slows whisker growth. Isothermal aging at moderate temperature $\left(50^{\circ} \mathrm{C}\right)$ leads to formation of the largest number of whiskers.

\section{ACKNOWLEDGEMENTS}

Authors would like to thank the Department of Science and Technology (DST), India, for financial support (grant \# DSTO 1164).

\section{ELECTRONIC SUPPLEMENTARY MATERIAL}

The online version of this article (doi:10.1007/ s11664-014-3622-3) contains supplementary material, which is available to authorized users.

\section{REFERENCES}

1. G.T. Galyon, IEEE Trans. Electron. Packag. Manuf. 28, 94 (2005).

2. H.L. Cobb, Mon. Rev. Am. Electroplaters Soc. 33, 28 (1946).

3. K.G. Compton, A. Mendizza, and S.M. Arnold, Corrosion 7, 327 (1951).

4. M. Fisher, L.S. Darken, and K.G. Carroll, Acta Metall. 2, 368 (1954).

5. K.N. Tu and J.C.M. Li, Mater. Sci. Eng. A 409, 131 (2005).

6. H. Leidecker and J. Brusse, Tin Whiskers: A History of Documented Electrical System Failures-A Briefing, Space Shuttle Program Office (2006), http://nepp.nasa.gov/whisker.

7. S.M. Arnold, in Proc. IEEE Electron. Comp. Conf. (1959), p. 75 .

8. S.M. Arnold, Plating 53, 96 (1966).

9. N. Jadhav, J. Wasserman, F. Pei, and E. Chason, J. Electron. Mater. 41, 588 (2012).
10. A. Baated, K. Hamasaki, S. Kim, K.-S. Kim, and K. Suganuma, J. Electron. Mater. 40, 2278 (2011).

11. Directive 2002/95/Ec of the European Parliament and of the council of 27 January 2003 on the restriction of the use of certain hazardous substances in electrical and electronic equipment (2003), http://eur-lex.europa.eu/LexUriServ/ LexUriServ.do?uri=OJ:L:2003:037:0019:0023:en:PDF.

12. M. Sobiech, U. Welzel, E.J. Mittemeijer, W. Hügel, and A. Seekamp, Appl. Phys. Lett. 93, 011906 (2008).

13. M.W. Barsoum, E.N. Hoffman, R.D. Doherty, S. Gupta, and A. Zavaliangos, Phys. Rev. Lett. 20, 206104 (2004).

14. E. Chason, N. Jadhav, W.L. Chan, L. Reinbold, and K.S. Kumar, Appl. Phys. Lett. 92, 171901 (2008).

15. C.H. Pitt and R.G. Henning, J. Appl. Phys. 35, 459 (1964).

16. N. Furuta and K. Kamamura, J. Appl. Phys. 8, 1404 (1969).

17. W. Sears, Acta Metall. 3, 367 (1955).

18. B.Z. Lee and D.N. Lee, Acta Mater. 46, 3701 (1998).

19. J. Smetana, IEEE Trans. Electron. Packag. Manuf. 30, 11 (2007).

20. P. Sarobol, J.E. Blendell, and C.A. Handwerker, Acta Mater. 61, 1991 (2013).

21. M. Sobiech, M. Wohlschlögel, U. Welzel, E.J. Mittemeijer, W. Hügel, A. Seekamp, W. Liu, and G.E. Ice, Appl. Phys. Lett. 94, 221901 (2009).

22. T.R. Bieler, B. Zhou, L. Blair, A. Zamiri, P. Darbandi, F. Pourboghrat, T.K. Lee, and K.C. Liu, J. Electron. Mater. 41, 283 (2012).

23. V.K. Glazunova and N.T. Kudryavtsev, Zh. Prikl. Khim. 36, 543 (1963) (Translated from Russian).

24. S. Lal and T.D. Moyer, IEEE Trans. Electron. Packag. Manuf. 28, 63 (2005).

25. K.S. Kim, J.H. Kim, and S.W. Han, Mater. Lett. 62, 1867 (2008).

26. C.V. Thompson, Mater. Sci. Eng. B 32, 211 (1995).

27. C.V. Thompson and R. Carel, J. Mech. Phys. Solids 44, 657 (1996).

28. P. Sarobol, A.E. Pedigo, P. Su, John.E. Blendell, and C.A. Handwerker, IEEE Trans. Electron. Packag. Manuf. 33, 159 (2010).

29. A. Frye, G.T. Galyon, and L. Palmer, IEEE Trans. Electron. Packag. Manuf. 30, 2 (2007).

30. S.P. Kim, H.M. Choi, and S.K. Choi, Thin Solis Films 332, 298 (1998).

31. H. Lou and Y. Huang, Electroplating, Encyclopedia of Chemical Processing, Vol. 839 (New York: Taylor and Francis, 2006) 3.

32. ASTM E112-13, Standard test methods for determining average grain size, http://www.astm.org/Standards/E112 .htm.

33. G.F. Vander Voort and A.M. Gokhale, Scripta Mater. 26, 1655 (1992).

34. M. Schlesinger and M. Paunovic, Modern Electroplating (New York: Wiley, 2010), p. 296.

35. F. Ebrahimi and Z. Ahmed, J. Appl. Electrochem 33, 733 (2003).

36. Á. Cziráki, B. Fogarassy, I. Gerőcs, and I. Bakonyi, J. Mater Sci. 29, 4771 (1994).

37. T. Jiang, N. Hall, A. Ho, and S. Morin, Thin Solid Films 471, 76 (2005).

38. S.S. Djokić, ECS Trans. 1, 1 (2006).

39. J. Chang, S.K. Kang, J.H. Lee, K.S. Kim, and H.M. Lee, J. Electron. Mater. 43, 259 (2014).

40. B.D. Dunn, A Laboratory Study of Tin Whisker Growth, (ESA STR-223, 1987).

41. J.B. LeBret and M.G. Norton, J. Mater. Res. 18, 585 (2003).

42. T. Kakeshita, R. Kawanaka, and T. Hasegawa, J. Mater. Sci. 17, 2560 (1982).

43. H. Garich, H. McCrabb, E.J. Taylor, and M. Inman, ECS Trans. 6, 153 (2007).

44. C.R.M. Grovenor, H.T.G. Hentzells, and D.A. Smith, Acta Metall. 32, 773 (1984).

45. H. Savaloni, M.A. Player, E. Gu, and G.V. Marr, Vacuum 43, 965 (1992). 
46. A.B. Kuper, D. Lazarus, J.R. Manning, and C.T. Tomizuka, Phys. Rev. 104, 1536 (1956).

47. F.H. Huang and H.B. Huntington, Phys. Rev. 9, 1479 (1974).

48. C.G. Zoski, Handbook of Electrochemistry (Boston: Elsevier, 2007), p. 817.

49. M.A. Ashworth, G.D. Wilcox, R.L. Higginson, R.J. Heath, C. Liu, and R.J. Mortimer, J. Electron. Mater. 43, 1005 (2014).

50. B. Jiang and A.P. Xian, Philos. Mag. Lett. 87, 657 (2007).

51. M. Liu and A.P. Xian, J. Electron. Mater. 38, 2353 (2009).

52. P. Sarobol, A. Pedigo, J. Blendell, and C. Handwerker, A synchrotron micro-diffraction investigation of crystallographic texture of high-sn alloy films and its effects on whisker growth, in IEEE Electronic Components and Technology Conference, 2010.

53. M.S. Sellers, A.J. Schultz, C. Basaran, and D.A. Kofke, Appl. Surf. Sci. 256, 4402 (2010).

54. K. Tsuji, in Proc. IPC-JEDEC Conf., Frankfurt, Germany, (2003), p. 169.

55. W.J. Boettinger, C.E. Johnson, L.A. Bendersky, K.W. Moon, M.E. Williams, and G.R. Stafford, Acta Mater. 53, 5033 (2005).

56. K.N. Tu, Acta Metall. 21, 347 (1973).

57. V.T. Deshpande and D.B. Sirdeshmukh, Acta Cryst. 14, 355 (1961).

58. P.D. Merica and L.W. Schad, Bull. Bureau Stand. 14, 571 (1918). 